\title{
Bottlenecks and loss of genetic diversity: spatio-temporal patterns of genetic structure in an ascidian recently introduced in Europe
}

\author{
R. Pérez-Portela ${ }^{1,2, *}$, X. Turon ${ }^{2}$, J. D. D. Bishop ${ }^{3}$ \\ ${ }^{1}$ Department of Animal Biology (Invertebrates), Faculty of Biology, University of Barcelona, 08028 Barcelona, Spain \\ ${ }^{2}$ Center for Advanced Studies of Blanes (CEAB-CSIC), Blanes, 17300 Girona, Spain \\ ${ }^{3}$ Marine Biological Association of United Kingdom, The Laboratory, Citadel Hill, Plymouth, PL1 2PB, UK
}

\begin{abstract}
We explored temporal patterns of genetic diversity and spatial genetic structure of the recently introduced ascidian Perophora japonica Oka, 1927 in Europe. A fragment of the mitochondrial gene cytochrome $c$ oxidase subunit I (COI) was sequenced for 291 colonies of one population in Plymouth, UK, which was monitored for 9 yr after its initial discovery. A total of 238 colonies from 12 localities were also sequenced for population structure analyses. The temporal monitoring of the Plymouth population showed a progressive loss of genetic diversity over time attributable to a strong initial bottleneck followed by genetic drift and/or selection. Population genetic structure was consistent with the historical records of this introduction, which probably originated from oyster farming activities in France, from where the species spread to the UK and Spain. Only one population in France displayed high levels of genetic diversity, and most of the remaining populations presented very low variability. In addition, significant differentiation in terms of allele frequencies was detected between some populations. $P$. japonica has suffered a loss of genetic diversity in both space and time since its introduction, but this did not prevent its expansion. Accidental human transport is the most likely mechanism of spread within the introduced range. Asexual propagation modes and chimerism in this species may play an important role in introduction events. The genetic data presented here can contribute to the design of more efficient management methods for this and similar introduced species.
\end{abstract}

KEY WORDS: Introductions - Genetic diversity - Population genetics · Bottleneck · Chimerism · Ascidians $\cdot$ Genetic drift $\cdot$ Selection

Resale or republication not permitted without written consent of the publisher

\section{INTRODUCTION}

The effect of non-native species on natural marine ecosystems has been widely documented (e.g. Ruiz et al. 1997, Holland 2000, Provan et al. 2005, Wallentinus \& Nyberg 2007). Coastal waters are especially susceptible to invasion and are one of the most invaded systems on the planet (Ruiz et al. 2000, Grosholz 2002). Ballast water, fouling of ships' hulls and aquaculture activities are the 3 most important vectors of inoculation (Carlton \& Geller 1993). Whatever the pathway of initial introduction, which corre- sponds to a process of extra-range or pre-border dispersal (Wilson et al. 2009, Goldstien et al. 2010), postinoculation processes (i.e. post-border dispersal) are of utmost significance for the success of non-native species. Local and recreational ship traffic, natural larval dispersal and asexual propagation are important vectors of post-border dispersal (Wasson et al. 2001, Branch \& Steffani 2004, Goldstien et al. 2010). Thus, clarifying post-border processes can assist in effective prevention and management of introduced species. In this sense, a temporal perspective on the ecological and evolutionary processes that shape the 
establishment and effects of invasive species is of crucial importance (e.g. Novak 2007, Keller \& Taylor 2008). Time, however, is often a neglected dimension in studies of invasive species (Strayer et al. 2006).

Special attention has focused in recent years on the ecological mechanisms that enable the establishment and spread of marine introduced species (e.g. Stachowicz et al. 1999, 2002a, Wilson et al. 2009). Information on genetic structure of introduced populations has revealed important features of invasion events, such as timing and source or sources of introductions, pathways and vectors, as well as the importance of propagule pressure during the introduction process (e.g. Roman \& Palumbi 2004, Lockwood et al. 2005, Provan et al. 2005, Rius et al. 2008, Dupont et al. 2010). The long-held idea that introduced populations have low genetic diversity due to founder effects and bottlenecks has been challenged by the finding of unexpectedly high levels of genetic diversity in introduced populations, which is attributable to recurrent introductions from diverse sources (Lambrinos 2004, Roman \& Darling 2007, Dlugosch \& Parker 2008, Wilson et al. 2009). However, once the species leaves the entry points (in a marine context these are often harbours, marinas or aquaculture facilities; Glasby et al. 2007, Bulleri \& Chapman 2010), secondary spread is likely to be strongly bottlenecked owing to the stochasticity and habitat barriers found in post-border dispersal (Forrest et al. 2009). This can make genetic drift one of the most powerful forces driving the evolution of these populations and, together with the risk of inbreeding, may cause dramatic reduction in genetic diversity, thereby limiting the evolutionary potential of nonindigenous populations in their new range (Novak 2007).

Nonetheless, despite an appreciable number of genetic studies, the relationship between genetic diversity and introduction success has not yet been clearly established (Holland 2000, Tsutsui et al. 2000, Lee 2002, Roman \& Darling 2007). In addition, little research has focused on how genetic changes over time may influence the success of an introduction (Lee 2002, Novak 2007, Keller \& Taylor 2008). Most standard genetic studies on populations have disregarded temporal variation, and the implicit assumption is that the genetic structure of populations is mostly stable over time. Yet population genetics theory predicts a very fast evolution of introduced populations as a result of drift and because new environments present novel selective pressures from both biotic interactions and abiotic factors (Stachowicz et al. 1999, 2002b, Sakai et al. 2001, Strayer et al. 2006,
Keller \& Taylor 2008). The scarce ecological data available show that introductions are dynamic processes and the distribution of genetic variation can be expected to change over the course of the introduction process (Geller et al. 2010). Therefore, dynamic properties of populations within ecological time frames should be taken into consideration when investigators deal with invasive or introduced species. Data on the time course of genetic descriptors can help us to understand how genetic diversity influences the success and the evolution of nonnative populations and therefore provide information directly applicable to management of marine introductions. To our knowledge, this is the first detailed study of temporal change in genetic diversity over time of an introduced marine invertebrate.

Ascidians, which are recognized as being major invaders around the world (Dupont et al. 2007, Lambert 2007, Rius et al. 2008, Stefaniak et al. 2009, Zhan et al. 2010), have an important effect on natural ecosystems and economic implications (Lambert 2007). Perophora japonica Oka, 1927 is one of several introduced colonial ascidians found in European seas (Nishikawa et al. 2000, Arenas et al. 2006, Gittenberger 2007). The species' native range includes Japan and Korea (Nishikawa 1991) and the Sea of Japan coast of the Russian Federation close to Vladivostok (Sanamyan 1998). The European introduction of $P$. japonica seems to be relatively recent, and populations of the species were first recorded from the northwest coast France in 1982 and 1984 by Monniot \& Monniot (1985), who considered that the introduction was probably associated with the importation of the seaweed Sargassum muticum and/or Pacific oysters Crassostrea gigas from Japan and Korea. After its initial detection in NW Europe, the species was found by C. Monniot in the Arcachon harbour (Gironde, France) in 1992 (G. Bachelet pers. comm. to J. D. D. Bishop, 2000) and in a marina in Plymouth, UK, in 1999 (Nishikawa et al. 2000). A second population on the English Channel coast, in a small section of the Fleet Lagoon ca. $130 \mathrm{~km}$ east of Plymouth, was noted within 1 to 2 yr (Baldock \& Bishop 2001), and a third one was observed in a marina in Gosport, UK, in 2005 (J. D. D. Bishop, C. A. Wood \& L. Dupont pers. obs.). To date, the species has not been found farther north or east in the UK, but it was recorded in Guernsey in the Channel Islands in 2003 (R. Lord pers. comm.), in The Netherlands in 2004 (Faasse 2004) and NW Spain in 2008 (El Nagar et al. 2010). In the absence of targeted monitoring, P. japonica could easily be overlooked, as it is a small, seasonal, relatively inconspicuous species, and potentially could 
Fig. 1. Perophora japonica. Sampling locations in the UK, France and Spain. Pie charts represent haplotype frequencies for each population, and the size of chart segments is proportional to sample size (except for Plymouth). For the Plymouth population the change in haplotype frequencies during $9 \mathrm{yr}$ of monitoring is shown

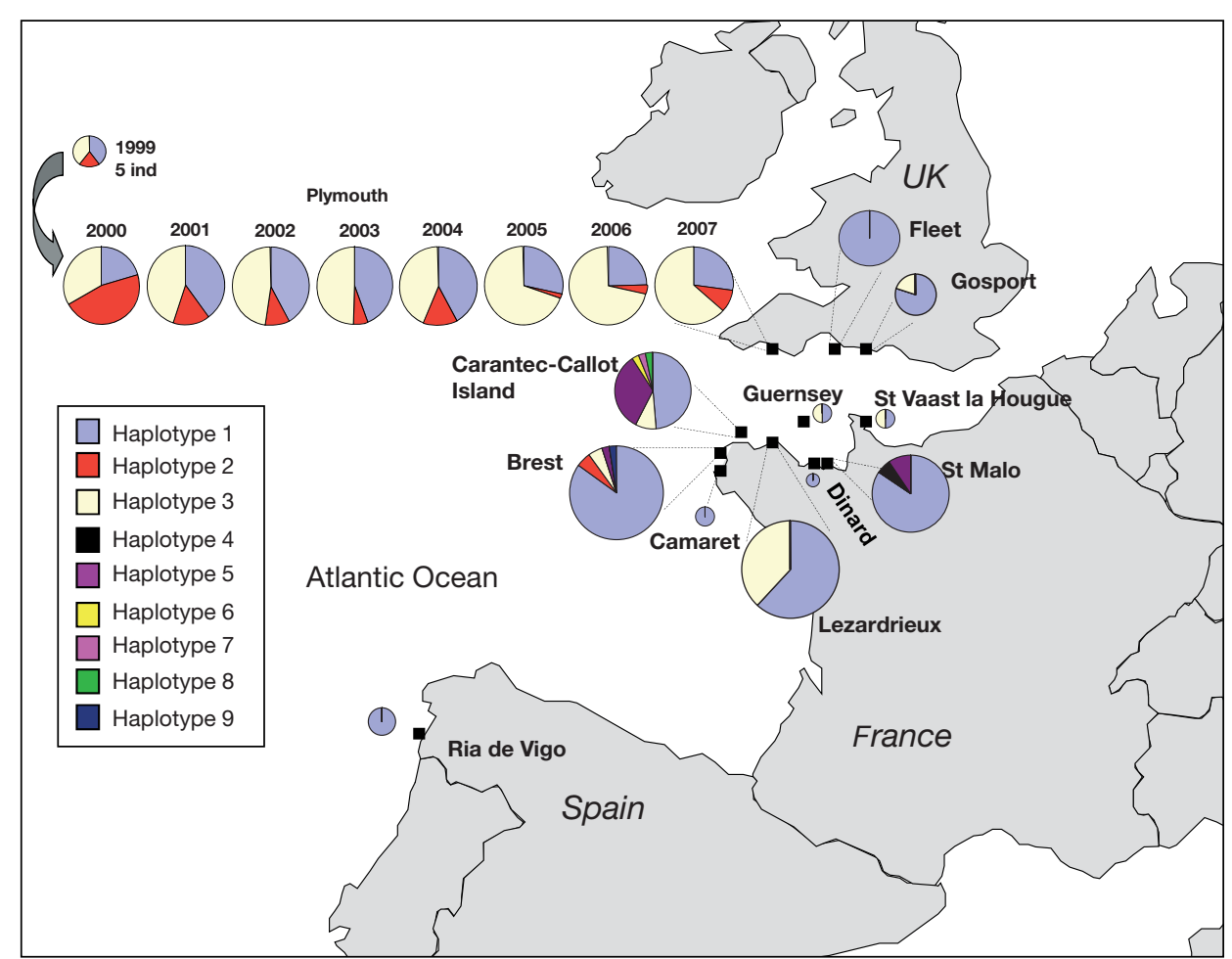

be confused on the European coast with the native congener $P$. listeri. Outside Europe, an introduced population of $P$. japonica was reported in the Pacific Ocean in Humboldt Bay, northern California, USA (Lambert 2005).

The different life history traits, ecological requirements, interactions with native species and diversity level in the new environment, as well as the initial genetic pool, may differentially influence species invasiveness (Grosholz \& Ruiz 1996, Stachowicz et al. 2002a, Grey 2011). Biological traits of the species promoting invasiveness include the ability to reproduce both sexually and asexually, rapid growth to sexual maturity, phenotypic plasticity, which allows high tolerance to the new environmental heterogeneity, and dispersal capacity (e.g. Kolar \& Lodge 2001, Sakai et al. 2001, Roman \& Darling 2007). Introductions can be thought of as 'natural' experiments in which we are able to observe the action of natural selection and the importance of contemporaneous demographic events during the colonization processes (Sakai et al. 2001, Novak 2007). Perophora japonica is an excellent study system, as its arrival in Europe is relatively recent and well documented. $P$. japonica also features an unusual mode of asexual dispersal through drifting buds (Mukai et al. 1983) that adds to its natural capabilities of dispersal via short-lived larvae. Furthermore, because the introduced population of $P$. japonica in a marina in Ply- mouth was detected at an early stage of colonization, the opportunity exists to evaluate temporal trends of genetic diversity in a new environment after inoculation.

To analyze the genetic structure in time and space of introduced populations of Perophora japonica in Europe, we selected the mitochondrial cytochrome $C$ oxidase subunit I gene (COI) because it offers a good level of genetic variation suitable for population genetic analyses (López-Legentil et al. 2006, PérezPortela \& Turon 2008, Stefaniak et al. 2009). The specific objectives of the present study were to (1) analyze temporal changes in genetic diversity of a population of $P$. japonica soon after its initial arrival in a non-native area in Europe and (2) explore the distribution of the genetic diversity of this species in NW Europe.

\section{MATERIALS AND METHODS}

\section{Sampling}

Temporal sampling

Perophora japonica was first noted in the UK in August 1999 during the monitoring of experimental panels at Queen Anne's Battery Marina (QAB) in Plymouth (Fig. 1). Samples of the population at that 
locality were collected annually from 1999 to 2007 during late summer or early autumn (August, September or October) when seasonal abundance was generally high. A total of 291 colonies were collected along ca. $210 \mathrm{~m}$ length of the outer pontoon at QAB. Colonies were collected on ropes and biota attached to the floats. Specimens were taken at least $1 \mathrm{~m}$ apart to reduce the chances of sampling clonal fragments of the same colony.

\section{Spatial sampling}

Between 2002 and 2005, a total of 236 samples of Perophora japonica were collected within the European introduced range from 11 different localities along the English Channel (the 46 individuals sampled in Plymouth in 2005 were shared with the temporal study). Additionally, 2 colonies were collected from Ría de Vigo in NW Spain in 2008 (see Fig. 1 and Table 1). One colony from the native area (from an aquaculture facility at Otsuchi Bay, Japan) was also sequenced for taxonomy confirmation. Most samples were obtained from artificial structures in marinas as described above, and in 2 instances (Carantec-Calloc and Fleet Lagoon) the samples were obtained from natural substrates. The sampling strategy included the 3 localities where the species was initially detected in 1982 and 1984 (Lézardrieux and Bay of Morlaix in Brittany, plus Saint-Vaast-la-Hougue in Normandy; Monniot \& Monniot 1985) and others where it appeared in later years, covering most of the introduced range known in Europe with the exception of The Netherlands.

With the exception of Dinard, where only a short section of pontoon was accessed, sampling effort was broadly similar at the different localities, so the number of colonies collected approximately reflected the abundance of Perophora japonica at the time of collection. This resulted in different sample sizes (Table 1). In particular, only 2 colonies were collected from Saint-Vaast, Dinard, Camaret, and Guernsey and also from Ría de Vigo in Spain. Only populations with more than 10 specimens sequenced and sampled in 2005 (with the exception of Lézardrieux, sampled in 2004) were used in spatial structure analyses.

Once in the laboratory, several zooids per colony from both the temporal and spatial sampling were preserved in $100 \%$ ethanol or EDTA (0.1 M, pH 7.9) at $-20^{\circ} \mathrm{C}$ until they were processed. Zooids with brooded larvae were avoided if alternatives were available or the larvae were removed.

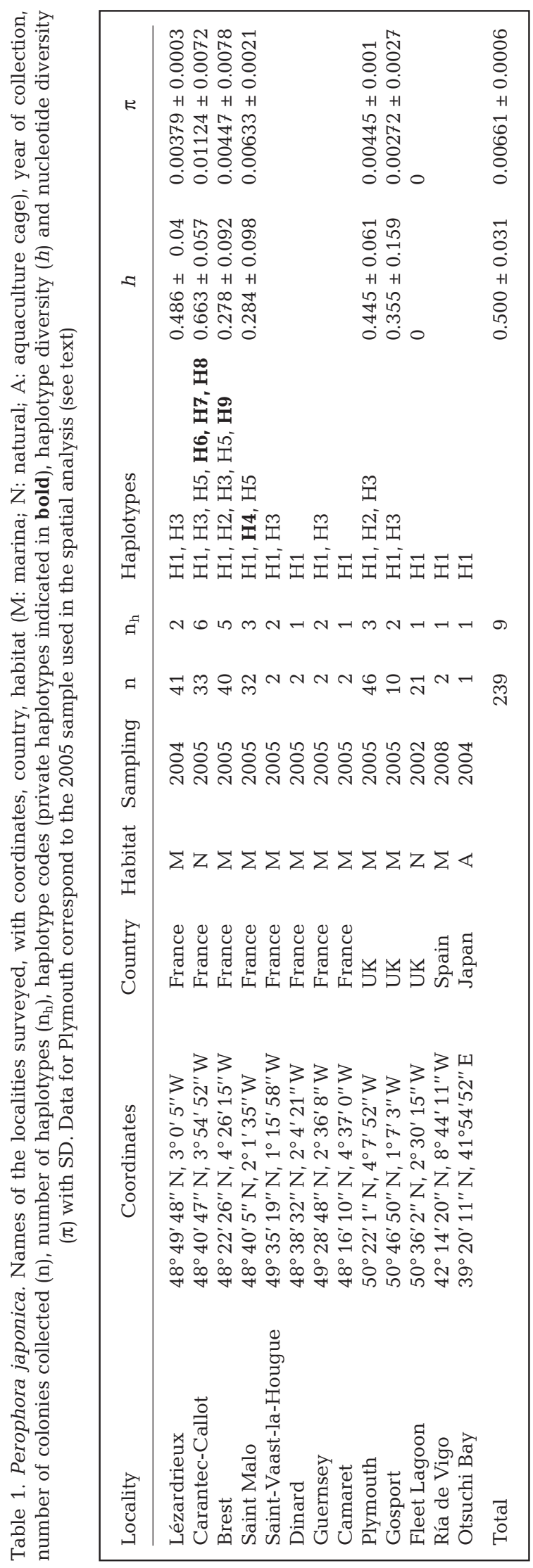




\section{DNA amplification and sequencing of $\mathrm{COI}$}

Total DNA was extracted from one zooid per colony by means of a protocol that used $1 \% \mathrm{~N}$-cetyl $\mathrm{N}, \mathrm{N}, \mathrm{N}$-trimethylammonium bromide (CTAB) buffer (2\% CTAB, 1.4 M NaCl, 20 mM EDTA, 100 mM Tris$\mathrm{HCl}, \mathrm{pH}$ 8.0) and included 2 chloroform-isoamyl extractions (Doyle \& Doyle 1987). Universal primers LCO1490 and HCO2198 described in Folmer et al. (1994) were used for the amplification of a fragment of the COI mitochondrial gene for the spatial study. Owing to unreliable amplification in some samples of the temporal study, a new pair of specific primers was designed with the program PRIMER 3.0 (available at http://primer3.sourceforge.net/, verified November 2011): PjF, 5'-TGC TGG TGT TGT TGG TAT GG-3', and PjR, 5'-AGC AGC CAA CAC AGG AAG AG-3'. The temporal analyses were performed on sequences obtained with this primer pair or, otherwise, trimmed to match this segment of COI.

The PCR amplification reaction was performed in a total volume of $20 \mu \mathrm{l}$ with $0.5 \mu \mathrm{l}$ of each primer (10 $\mu \mathrm{M}), 0.5 \mu \mathrm{l}$ dNTPs $(10 \mu \mathrm{M}), 4 \mu \mathrm{l} 5 \times$ buffer, $1.6 \mu \mathrm{l}$ $\mathrm{MgCl}_{2}$ (Promega, www.promega.com), $0.2 \mu$ FlexiTaq polymerase (Promega) and $0.5 \mu$ lemplate DNA. A single denaturation step at $94^{\circ} \mathrm{C}$ for 2 min was followed by 35 cycles (denaturation at $94^{\circ} \mathrm{C}$ for $45 \mathrm{~s}$, annealing at $55^{\circ} \mathrm{C}$ for $50 \mathrm{~s}$ and extension at $72^{\circ} \mathrm{C}$ for $55 \mathrm{~s}$ ) and a final extension at $72^{\circ} \mathrm{C}$ for $5 \mathrm{~min}$ in a PCT-200 DNA Engine Peltier thermal cycler. The same primers were used for the sequencing reaction in both directions (forward and reverse), and the PCR products were sequenced with an ABI Big-Dye Ready-Reaction Perkin Elmer kit on an ABI Prism 377XL automated sequencer (Applied Biosystems) by the Scientific and Technical Services, University of Barcelona.

All the sequences of the COI fragment were edited and aligned by using the Bioedit Sequence Alignment Editor (Hall 1999) and alignment was confirmed by eye. The nucleotide sequences obtained in this study have been deposited in Genbank (accession nos. JQ863390 to JQ863398; available at www.genbank.com).

\section{Data analysis}

Frequencies of haplotypes per population, and per year in the Plymouth population, were calculated with ARLEQUIN v. 3.11 (Excoffier et al. 2005). Nucleotide diversity $(\pi)$ and haplotype diversity $(h)$ (Nei 1987 ) were also computed for each year and population with DnaSP v. 4.10 (Rozas et al. 2003).
Temporal monitoring

We investigated genetic differences over time in the Plymouth population by using both the standard $F_{\text {ST }}$ statistic (with the estimator of Weir \& Cockerham 1984 ) and the new measure of differentiation $D$ proposed by Jost (2008), since the simultaneous use of both kinds of statistics has been advocated (Meirmans \& Hedrick 2011, Leng \& Zhang 2011). Pairwise $F_{\text {ST }}$ values were assessed with ARLEQUIN by using haplotype frequency data and their significance was calculated by performing 10000 permutations of the data set. The $D$ index was obtained by using the estimator in Eq. (13) of Jost (2008) with the SPADE software (available at http://chao.stat.nthu.edu.tw), and 10000 bootstrap replicates were run to estimate confidence intervals. A correction for multiple tests was made following the Benjamini and Yekutieli method as described in Narum (2006). The critical value obtained was used to assess significance of the p-values (in $F_{\mathrm{ST}}$ ) and to establish the width of the CI (in $D$ ) by using a normal approximation (in order to check whether the value of 0 , i.e. no differentiation, falls within this interval). A multidimensional scaling analysis (MDS) was performed to graphically visualize interrelationships in the matrix of distances derived from the $F_{\mathrm{ST}}$ values.

A linear regression analysis was performed to test whether variation in genetic diversity (haplotype diversity) was linearly related to time (in years). Data were checked for the assumptions of normality and homoscedasticity. The regression was done by including and excluding data from 1999 owing to the low number of sequences available for the first year.

Spatial analysis (population genetics)

The localities of Lézardrieux, Carantec-Callot, Brest, Saint Malo, Plymouth and Gosport were included in the population genetics analyses. To detect differences in genetic structure between populations we calculated and tested for significance the $F_{\mathrm{ST}}$ and $D$ statistics as described for the temporal analysis. Likewise, an MDS was performed on the matrix of $F_{\mathrm{ST}}$ values for a graphical depiction of the structure.

The effect of isolation by geographical distance was tested with the Mantel test procedure (Rousset 1997) and 10000 permutations were executed in ARLEQUIN. To test for genetic structure between the 2 sides of the English Channel, we performed an analysis of molecular variance (AMOVA) based on 
haplotype frequencies and pooled the populations into English and French groups. We ran 16000 permutations in ARLEQUIN to guarantee that there was less than $1 \%$ difference from the exact probability in $99 \%$ of cases.

Relationships between haplotypes were assessed by an unrooted network. We used the program Network (www.fluxus-engineering.com/ sharenet.htm), which employs the median-joining network method and assumes the absence of recombination (Bandelt et al. 1999). We used the criteria derived from coalescent theory (Templeton et al. 1987, Templeton \& Sing 1993) to resolve loops in the network.

\section{RESULTS}

The final length after alignment and trimming was $476 \mathrm{bp}$ for the temporal monitoring and $538 \mathrm{bp}$ for the population genetics analyses due to the use of different primer pairs. All sequences could be translated into amino acids without stop codons.

\section{Temporal monitoring}

A total of 3 haplotypes, H1, H2 and H3 (same notation as in the spatial study; see Table 1), were obtained from 291 sequences during the $9 \mathrm{yr}$ of monitoring the Plymouth (QAB) population (Table 2).

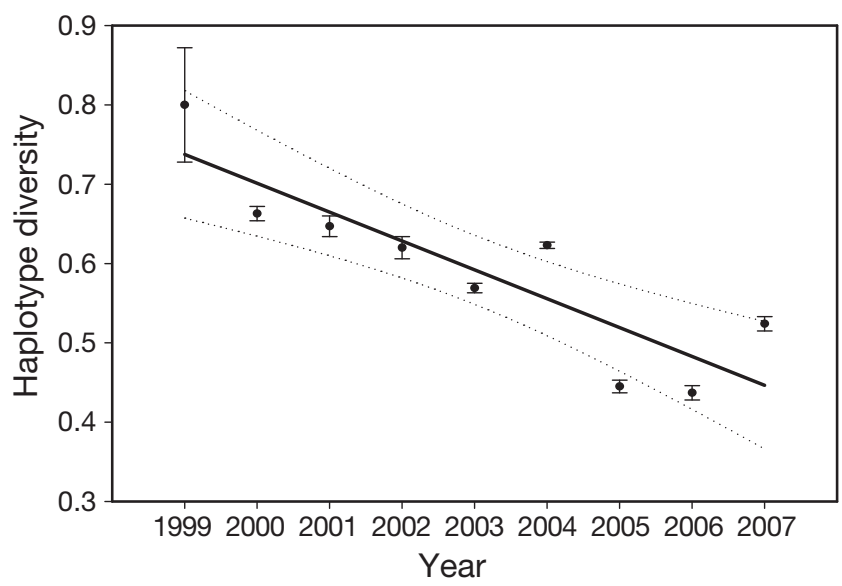

Fig. 2. Perophora japonica. Linear regression of mean $( \pm \mathrm{SD})$ haplotype diversity $(h)$ with time during $9 \mathrm{yr}$ of monitoring the Plymouth population. Dotted lines: CI
Table 2. Perophora japonica. Plymouth population over time showing year of collection, total number of individuals and numbers belonging to each haplotype (H1, H2 and H3), haplotype diversity $(h)( \pm \mathrm{SD})$ and nucleotide diversity $(\pi)( \pm$ SD) per year. See also Fig. 1

\begin{tabular}{|crrrrrrr}
\hline \multirow{2}{*}{ Year } & \multicolumn{9}{c}{ Number of individuals -} & & \multicolumn{2}{c}{ Genetic diversity } \\
& Total & H1 & H2 & H3 & & $h$ & $\pi$ \\
\hline 1999 & 5 & 2 & 1 & 2 & $0.800 \pm 0.164$ & $0.0124 \pm 0.0045$ \\
2000 & 24 & 5 & 11 & 8 & $0.663 \pm 0.048$ & $0.0141 \pm 0.0007$ \\
2001 & 20 & 8 & 3 & 9 & $0.647 \pm 0.057$ & $0.0099 \pm 0.0023$ \\
2002 & 19 & 8 & 2 & 9 & $0.620 \pm 0.061$ & $0.0085 \pm 0.0023$ \\
2003 & 34 & 15 & 2 & 17 & $0.569 \pm 0.040$ & $0.0066 \pm 0.0015$ \\
2004 & 50 & 21 & 7 & 22 & $0.623 \pm 0.032$ & $0.0093 \pm 0.0014$ \\
2005 & 46 & 13 & 1 & 32 & $0.445 \pm 0.061$ & $0.0044 \pm 0.0010$ \\
2006 & 49 & 12 & 2 & 35 & $0.437 \pm 0.066$ & $0.0049 \pm 0.0012$ \\
2007 & 44 & 12 & 4 & 28 & $0.524 \pm 0.062$ & $0.0072 \pm 0.00156$ \\
Total & 291 & 96 & 33 & 162 & $0.570 \pm 0.018$ & $0.0082 \pm 0.0006$ \\
& & & & & & & \\
\hline
\end{tabular}

Haplotype diversity and nucleotide diversity had a similar pattern of decrease over time (Table 2); maximal values occurred after the initial discovery of the species at QAB in 1999 and 2000, and lowest values occurred in the last 3 yr. During the 9 yr of monitoring, there was a significant decrease in haplotype diversity over time, which followed a linear trend (slope $=-0.364, \mathrm{r}=0.874, \mathrm{p}<0.0001$ ) (Fig. 2). When the 1999 data, obtained from only 5 colonies, was discarded from the analysis the regression was still highly significant (slope $=-0.297, \mathrm{r}=0.819$, $\mathrm{p}<0.0001$, not shown).

Haplotype H1 was the least frequent in 2000, but its frequency increased until 2004 and decreased afterwards. Conversely, haplotype $\mathrm{H} 2$ was the most frequent in 2000, but its frequency fell in 2001, and it remained at low frequency thereafter. Haplotype H3 was the only one with a generally increasing trend over time, although some episodic decreases were observed (Fig. 1).

The $F_{\mathrm{ST}}$ results demonstrated genetic differences between years during the monitoring period. Year 2000 showed significant differentiation from 2003, 2005, 2006 and 2007 based on the $F_{\mathrm{ST}}$ values, and only from 2005 and 2006 based on the $D$ estimator (Table 3). In the MDS plot, based on $F_{\mathrm{ST}}$ values, the year 2000 was separated from all the others, and a slight separation of the remaining years in 2 groups (1999 to 2004 and 2005 to 2007) was apparent (Fig. 3).

Two individuals from 2005 and one from 2006 had to be excluded from the analyses because they showed 'hybrid' sequences between the 2 most common haplotypes (H1 and H3). This result suggested that these colonies could be chimeras. Amplification and sequencing of those samples was repeated to 

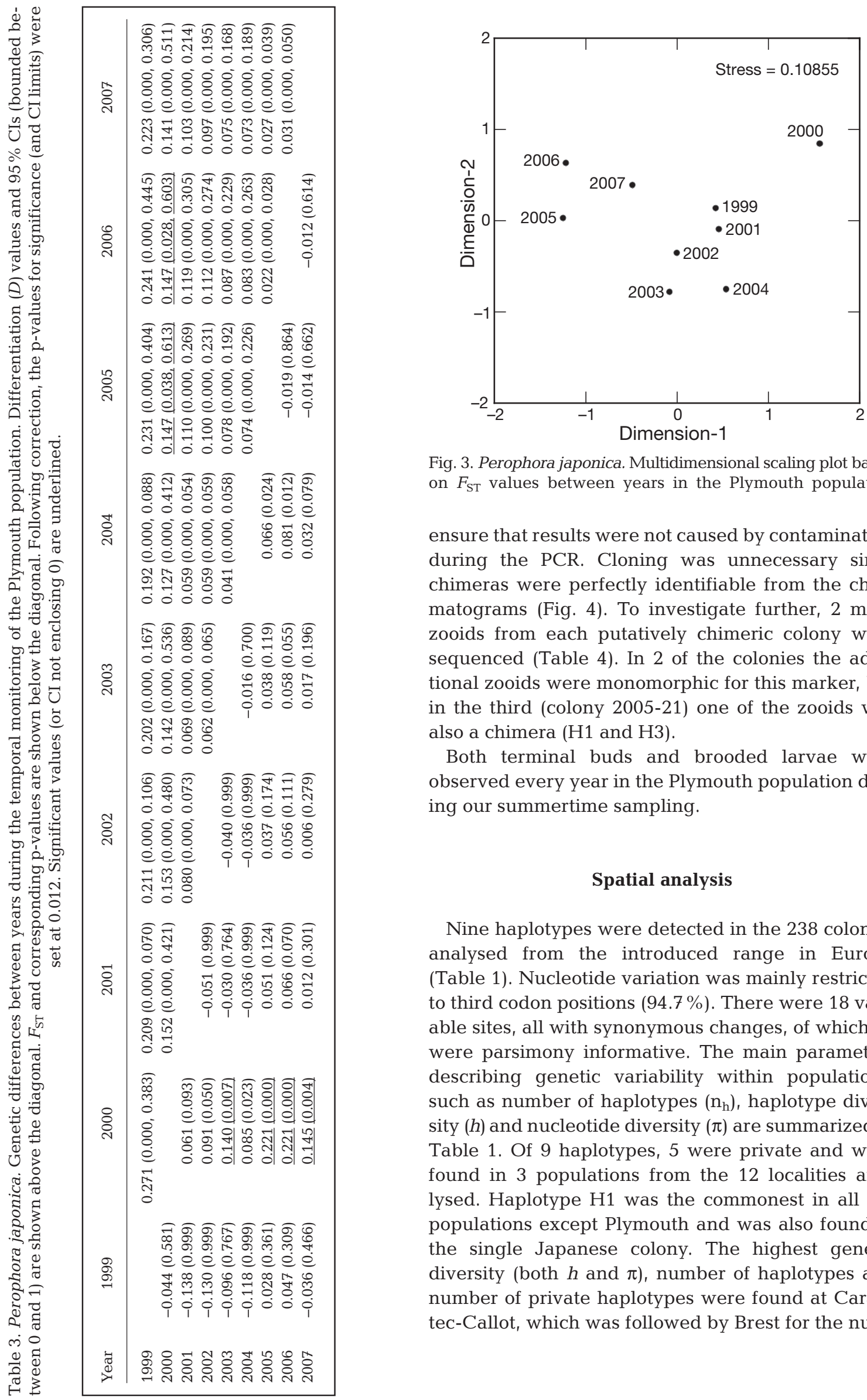

Fig. 3. Perophora japonica. Multidimensional scaling plot based on $F_{\mathrm{ST}}$ values between years in the Plymouth population

ensure that results were not caused by contamination during the PCR. Cloning was unnecessary since chimeras were perfectly identifiable from the chromatograms (Fig. 4). To investigate further, 2 more zooids from each putatively chimeric colony were sequenced (Table 4). In 2 of the colonies the additional zooids were monomorphic for this marker, but in the third (colony 2005-21) one of the zooids was also a chimera (H1 and H3).

Both terminal buds and brooded larvae were observed every year in the Plymouth population during our summertime sampling.

\section{Spatial analysis}

Nine haplotypes were detected in the 238 colonies analysed from the introduced range in Europe (Table 1). Nucleotide variation was mainly restricted to third codon positions $(94.7 \%)$. There were 18 variable sites, all with synonymous changes, of which 15 were parsimony informative. The main parameters describing genetic variability within populations, such as number of haplotypes $\left(\mathrm{n}_{\mathrm{h}}\right)$, haplotype diversity $(h)$ and nucleotide diversity $(\pi)$ are summarized in Table 1. Of 9 haplotypes, 5 were private and were found in 3 populations from the 12 localities analysed. Haplotype H1 was the commonest in all the populations except Plymouth and was also found in the single Japanese colony. The highest genetic diversity (both $h$ and $\pi$ ), number of haplotypes and number of private haplotypes were found at Carantec-Callot, which was followed by Brest for the num- 
$\begin{array}{rrrrr}\mathbf{5 5 0} & \mathbf{5 6 0} & \mathbf{5 7 0} & \mathbf{5 8 0} & \mathbf{5 9 0}\end{array}$

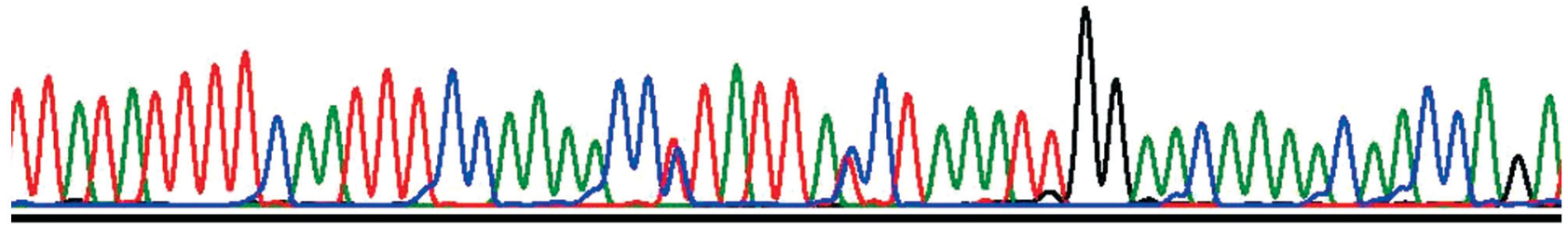

Fig. 4. Perophora japonica. Fragment of a sequencing chromatogram of an apparent chimera with double peaks (at positions 570 and 576) due to the presence of 2 different haplotypes (H1 and H3) of the cytochrome $c$ oxidase subunit I (COI)

Table 4. Perophora japonica. Apparent chimeras in Plymouth time-series samples; results of the zooids sequenced for 2 colonies from 2005 and 1 colony from 2006

\begin{tabular}{|llcl|}
\hline \multirow{2}{*}{ Colony code } & \multicolumn{3}{c|}{ Haplotype } \\
\cline { 2 - 4 } & Zooid 1 & Zooid 2 & Zooid 3 \\
\hline $2005-20$ & H1 + H3 & H3 & H3 \\
$2005-21$ & H1 + H3 & H3 & H1 + H3 \\
$2006-06$ & H1 + H3 & H1 & H1 \\
& & & \\
\hline
\end{tabular}

ber of haplotypes, although this locality had one of the lowest haplotype diversities of the populations analysed owing to the dominance of H1. The Fleet population was monomorphic for $\mathrm{H} 1$ (see Fig. 1, Table 1).

The statistic $F_{\mathrm{ST}}$ revealed that Carantec-Callot, Lézardrieux and Plymouth were genetically differentiated from most other populations (Table 5). Only Gosport did not show significant differences with the 2 French populations. However, the $D$ estimator only detected significant differences between Plymouth and the 3 populations in which H3 was not frequent (Brest, Carantec-Callot and Saint Malo). The MDS plot did not show separation between English and French populations (Fig. 5), but Carantec-Callot appeared slightly set apart from the other populations.

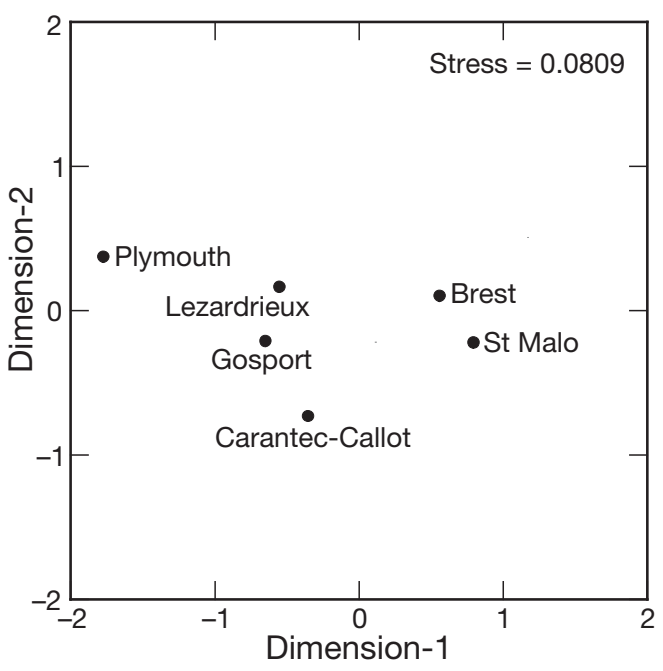

Fig. 5. Perophora japonica. Multidimensional scaling plot based on $F_{\mathrm{ST}}$ values between introduced populations

No signal of isolation by distance was detected in the area studied (Mantel test: $\mathrm{r}=-0.061, \mathrm{p}=0.575$ ).

The AMOVA revealed that the component of genetic variance associated with the 2 sides of the English Channel (18\%) was non-significant (Table 6). Most of the variance observed $(66 \%)$ was concentrated within populations, and $15 \%$ of the variance

Table 5. Perophora japonica. Population genetic differentiation in Europe. Differentiation $(D)$ values and CIs (bounded between 0 and 1 ) are shown above the diagonal. $F_{\mathrm{ST}}$ and corresponding $\mathrm{p}$-values are shown below the diagonal. Following correction, the p-values for significance (and CI limits) were set at 0.015. Significant values (or CI not enclosing 0) are underlined

\begin{tabular}{|c|c|c|c|c|c|c|}
\hline Locality & Lezardrieux & Brest & Carantec-Callot & Saint Malo & Plymouth & Gosport \\
\hline Lezardrieux & & $0.126(0.00-0.32)$ & $0.217(0.00-0.45)$ & $0.156(0.00-0.35)$ & $0.174(0.00-0.43)$ & $0.017(0.00-0.24)$ \\
\hline Brest & $\underline{0.166} \underline{(0.002)}$ & & $0.204(0.00-0.45)$ & $0.000(0.00-0.03)$ & $\underline{0.570} \underline{(0.32-0.82)}$ & $0.000(0.00-0.25)$ \\
\hline Carantec- Callot & $\underline{0.141} \underline{(0.001)}$ & $\underline{0.189}(0.000)$ & & $0.164(0.00-0.41)$ & $\underline{0.551} \underline{(0.27-0.83)}$ & $0.173(0.00-0.43)$ \\
\hline Saint Malo & $\underline{0.194} \underline{(0.000)}$ & $-0.003(0.446)$ & $\underline{0.153} \underline{(0.002)}$ & & $\underline{0.625} \underline{(0.39-0.86)}$ & $0.007(0.00-0.16)$ \\
\hline Plymouth & $\underline{0.167} \underline{(0.003)}$ & $\underline{0.496} \underline{(0.000)}$ & $\underline{0.315} \underline{(0.000)}$ & $\underline{0.510} \underline{(0.000)}$ & & $0.391(0.00-0.81)$ \\
\hline Gosport & $0.011(0.460)$ & $-0.013(0.554)$ & $0.110(0.550)$ & $0.025(0.306)$ & $\underline{0.349}(0.003)$ & \\
\hline
\end{tabular}


Table 6. Perophora japonica. Analysis of molecular variance grouping populations according to the side of the English Channel on which they occur: England ( 2 populations) and France (4 populations)

\begin{tabular}{|lcccc|}
\hline Source of variation & df & $\begin{array}{c}\text { Sum of } \\
\text { squares }\end{array}$ & $\begin{array}{c}\text { Variance } \\
\text { components }\end{array}$ & Percentage of variation \\
\hline Among groups & 1 & 6.795 & 0.059 & $18.34\left(F_{\mathrm{CT}}=0.183, \mathrm{p}=0.66\right)$ \\
$\begin{array}{l}\text { Among populations } \\
\quad 4\end{array}$ & 6.810 & 0.048 & $15.03\left(F_{\mathrm{SC}}=0.184, \mathrm{p}=0.000\right)$ \\
$\quad$ within groups & & & & \\
$\begin{array}{l}\text { Within populations } \\
\text { Total }\end{array}$ & 194 & 41.290 & 0.213 & $66.62\left(F_{\mathrm{ST}}=0.334, \mathrm{p}=0.000\right)$ \\
& 199 & 54.895 & 0.319 & \\
\end{tabular}

\section{DISCUSSION}

The monitoring of the QAB population in Plymouth provided information about the temporal trends of genetic diversity in an introduced marine invertebrate. Previous information suggests that, in many cases, genetic diversity can increase over time as the result of multiple introduction events (reviewed in Roman \& Darling 2007). In our case, we found a strong initial bottleneck (three haplotypes) and an apparent lack of new introductions, as the same haplotypes were found throughout the monitoring period. This indicated that QAB did not have recurrent inflow from other populations, either because no new propagules arrived or, alternatively, because invasion resistance occurred, which would have impeded the establishment of newcomers (Stachowicz et al. 1999, 2002a). In addition, the molecular results showed a linear reduction of genetic diversity due to the increasing dominance of one haplotype (which was not the commonest in the introduced range). The changes in allele frequency observed may be due to either genetic drift or selection (on linked loci, as the substitutions observed in this study were all synonymous). Assessing the relative importance of these 2 forces in the evolution of invasive populations is difficult to assess (Novak 2007, Keller \& Taylor 2008) and cannot be addressed in our case with the present data. Overall, a bottleneck suffered by the population (consistent also with the low initial abundance in 1999) could have been aggravated in subsequent years by genetic drift and/or selection, resulting in decreased diversity over time.

Despite the decrease in genetic diversity detected in the QAB population and the associated risk of inbreeding depression, Perophora japonica was able to successfully establish itself and become relatively abundant within the sampled area of the marina during the later years of monitoring. Both terminal buds and brooded larvae were observed every year in summertime. Sexual and asexual reproduction, combined
Fig. 6. Perophora japonica. Median-joining network of cytochrome $c$ oxidase subunit I (COI) haplotypes. Circle areas are proportional to the number of sampled individuals. Segments inside the circles represent the proportion of each population within each haplotype. Crossed $(x)$ circles represent missing, probably unsampled haplotypes, or extinct sequences. Roman numerals represent the number of mutation steps when there is more than one 
with stolonial vegetative spreading, could all have contributed to persistence of this population and to the high summer abundances sometimes reached. However, the Fleet Lagoon population (with only 1 haplotype) went extinct 3 to $5 \mathrm{yr}$ after detection, despite the high local abundance achieved by the species, and has not reappeared (J. D. D. Bishop pers. obs.). Lack of genetic diversity may limit the evolutionary potential of the species (Novak 2007) so that the much depleted diversity of the Fleet population could have restricted the viability of $P$. japonica in this locality. This particular example suggests that, although the relationship between genetic diversity and introduction success is not always straightforward (Roman \& Darling 2007), there may be a diversity threshold below which populations are unable to adapt to new environments and so may more easily succumb to stochastic environmental variation (Lee 2002).

Our molecular results are consistent with historical records of the introduction of Perophora japonica in Europe given by Monniot \& Monniot (1985). Those authors suggested that the introduction was probably associated with oyster mariculture and/or the introduction of the alga Sargassum muticum. The Carantec-Callot population in Brittany, reported as one of the first introduced populations in Europe (Monniot \& Monniot 1985), had the highest genetic diversity together with the highest number of private haplotypes in the introduced range. The remaining populations had lower genetic diversities and no private haplotypes (except one each in Brest and Saint Malo). The moderate to high level of genetic diversity in the Carantec-Callot population suggests that an initial inoculum of large size reached the area, which supports the hypothesis that oyster farming was a vector of the species introduction. Commercial shellfish transplantation has the capacity to transport and deliver large propagule pools, in which a high proportion of native genetic diversity is retained (Roman \& Palumbi 2004, Roman \& Darling 2007).

Comparisons of genetic composition of introduced populations with native ones can provide information about the colonization process, but, in this particular case, we lack information on the genetic variability of Perophora japonica in its native range. However, values of genetic diversity of COI for $P$. japonica in Carantec-Callot were comparable with those of some native species of colonial ascidians in Europe, such as Cystodytes dellechiajei and Pycnoclavella communis (López-Legentil \& Turon 2006, Pérez-Portela \& Turon 2008), but lower than that for other introduced species such as Botryllus schlosseri (Ben-Shlomo et al. 2006, López-Legentil et al. 2006) and Microcosmus squamiger (Rius et al. 2008), in which multiple introductions with genetic admixture from diverse sources have been assumed.

Our results suggest that the introduction originated from a single arrival followed by a secondary spread to adjacent regions. NW Brittany, as represented in the present sampling at Carantec-Callot and Brest, acted as a source for post-border dispersal along the English Channel, but only 3 haplotypes from Brittany reached southern England. The existence of successive secondary introductions (introductions sourced by populations that are themselves introduced) in marine bioinvasions draws attention to the fact that not all sources are native (Darling et al. 2008). Since secondarily invading populations often contain a small proportion of the total genetic diversity of their source population (Roman \& Darling 2007, Dlugosch \& Parker 2008), after successive bottlenecks and genetic drift the newly established populations are likely to be much less diverse than the population from which they were derived (Holland 2000, Sakai et al. 2001, Dupont et al. 2007). In particular, the less abundant haplotypes in the initial populations are likely to be lost during subsequent spreading of the species, as happened in our case.

Both $F_{\mathrm{ST}}$ and $D$ statistics revealed significant genetic differences between the populations of Perophora japonica, although the former detected more significant outcomes in pairwise comparisons. Bottlenecking, drift and selection in introduced populations may promote rapid divergence in haplotype frequencies even if populations are derived from the same sources. The genetic differentiation detected between some nearby populations may therefore be the result of demographic events related to the colonization process coupled with low connectivity between them. Isolation by distance was not detected at the scale studied, which reinforces the probable role of artificial transport between harbours, since localities along the English Channel are regularly connected by sea traffic. Colonial ascidians have a short larval stage and hence low dispersal capacity (Svane \& Young 1989), so the natural interchange of larvae between areas within the introduced range is quite unlikely. Similar patterns of population genetic differentiation have been observed for other introduced ascidian species (e.g. LópezLegentil et al. 2006, Rius et al. 2008, Dupont et al. 2009, 2010, Pineda et al. 2011, but see Zhan et al. 2010, Bock et al. 2011).

One of the most important challenges for the management of invasive and introduced species is to 
understand the evolutionary and ecological causes responsible for their spread (Zhan et al. 2010). Both the genetic structure of populations and the life history of the species can affect the efficacy of invasion control (Sakai et al. 2001). Perophora japonica has a unique mechanism of colony multiplication that occurs through the drifting of stellate buds (Mukai et al. 1983). Asexual dispersive stages are extremely rare in ascidians (Fujimoto \& Watanabe 1976, Turon 2005) and may have important roles in colonization processes. Although drifting buds are unlikely to travel great distances, they can be important in colonizing and monopolizing space once individuals have arrived at a new site, as the success of an exotic species depends heavily on its capacity to initiate a new population from a few individuals (Dupont et al. 2007). On the other hand, clonal propagation can genetically homogenize populations of weedy plant species, which makes biological control of these species more effective than for sexually reproducing species (Burdon \& Marshall 1981, Sakai et al. 2001).

Fusion has been described in a number of colonial ascidians (see Bishop \& Sommerfeldt 1999 for a compilation of earlier published records; Ben-Shlomo et al. 2001, Sommerfeldt et al. 2003), including Perophora japonica (Koyama \& Watanabe 1981, 1986), and can result in the formation of chimeras, i.e. genetically composite entities (Sommerfeldt et al. 2003, Rinkevich 2005). In Botryllinae (Family Styelidae) and Perophoridae, zooids within colonies are linked by common vascular systems (Bishop \& Sommerfeldt 1999, Pérez-Portela et al. 2009) that fuse when chimeras are formed, thereby allowing haemolymph cells from different genotypes to circulate between fusion partners (Watanabe \& Taneda 1982, Koyama \& Watanabe 1986). In P. japonica fusion of different stolons of the same colony has been documented during the growth of reared colonies (Koyama \& Watanabe 1981, 1986) and presumably results in the lattice-like array of interconnected stolons seen in wild colonies. The apparent documentation of chimerism in the present study suggests that the stolons of different colonies may sometimes fuse in $P$. japonica. This has been demonstrated in $P$. sagamiensis, in which inter-colony contact results in fusion rather than rejection in a minority of pairings (Koyama \& Watanabe 1982), perhaps because the self-nonself recognition process sometimes fails in the case of contact between relatives. The potential costs and benefits of chimerism are a matter of debate (Rinkevich \& Weissman 1992, Rinkevich 2005), but a commonly postulated benefit may be a higher genetic variability that can improve adaptive responses (reviewed in Rinkevich 2005). Although our marker is unsuitable for a quantitative study of chimerism, the observed mitochondrial heteroplasmy in zooids of $P$. japonica is likely to be the result of exchange of blood-borne cells among fused colonies. The extent and ecological significance of chimerism in the context of introduced populations remains an open question that deserves specific study.

In conclusion, our results suggest a picture of genetically rich 'reservoirs' of Perophora japonica from which other areas are seeded at the cost of loss of diversity. These localized source populations thus provide potential intervention points where vector management, eradication procedures and other control activities may be undertaken for effective management of introduced species.

Acknowledgements. This research was supported by a postdoctoral grant from foundation FUNDAME and a 'Beatriu de Pinós' contract (Comissionat per a Universitats i Recerca from Departament d'Innovació, Universitats i Empresa, Generalitat de Catalunya) to R.P.P. Funding was provided by project CTM2010-22218 (BENTHOMICS) of the Ministry of Science from the Spanish Government, the EU FP6 Network of Excellence 'Marine Genomics', the NERC Oceans 2025 programme and the AXA Research Fund 'Marine Aliens and Climate Change' project. We thank L. Dupont, F. Viard, T. Nishikawa, A. El Nagar, R. Huys, C. Wood, G. Lambert, C. Lambert and L. Baldock for sending samples or collaborating with sample collection.

\section{LITERATURE CITED}

Arenas F, Bishop JDD, Carlton JT, Dyrynda PJ and others (2006) Alien species and other notable records from a rapid assessment survey of marinas on the south coast of England. J Mar Biol Assoc UK 86:1329-1337

Baldock B, Bishop JDD (2001) Occurrence of the non-native ascidian Perophora japonica in the Fleet, southern England. J Mar Biol Assoc UK 81:1067

Bandelt HJ, Forster P, Rohl A (1999) Median-joining networks for inferring intraspecific phylogenies. Mol Biol Evol 16:37-48

Ben-Shlomo R, Douck J, Rinkevich B (2001) Heterozygote deficiency and chimerism in remote populations of a colonial ascidian from New Zealand. Mar Ecol Prog Ser 209:109-117

> Ben-Shlomo R, Paz G, Rinkevich B (2006) Postglacial-period and recent invasions shape the population genetics of botryllid ascidians along European Atlantic coasts. Ecosystems 9:1118-1127

Bishop JDD, Sommerfeldt DA (1999) Not like Botryllus: indiscriminate post-metamorphic fusion in a compound ascidian. Proc R Soc Lond B Biol Sci 266:241-248

Bock DG, Zhan A, Lejeusne C, MacIsaac HJ, Cristescu ME (2011) Looking at both sides of the invasion: patterns of colonization in the violet tunicate Botryllus violaceus. Mol Ecol 20:503-516

Branch GM, Steffani CN (2004) Can we predict the effects of alien species? A case-history of the invasion of South 
Africa by Mytilus galloprovincialis (Lamarck). J Exp Mar Biol Ecol 300:189-215

Bulleri F, Chapman MG (2010) The introduction of coastal infrastructure as a driver of change in marine environments. J Appl Ecol 47:26-35

Burdon JJ, Marshall DR (1981) Biological control and the reproductive mode of weeds. J Appl Ecol 18:649-659

> Carlton JT, Geller B (1993) Ecological roulette: the global transport of nonindigenous marine organisms. Science 261:78-82

Darling JA, Bagley MJ, Roman J, Tepolt CK, Geller JB (2008) Genetic patterns across multiple introductions of the globally invasive crab genus Carcinus. Mol Ecol 17: 4992-5007

> Dlugosch KM, Parker M (2008) Founding events in species invasions: genetic variation, adaptive evolution, and the role of multiple introductions. Mol Ecol 17:431-449

Doyle JJ, Doyle JL (1987) A rapid DNA isolation procedure for small quantities of fresh leaf tissue. Phytochem Bull 19:11-15

> Dupont L, Viard F, David P, Bishop JDD (2007) Combined effects of bottlenecks and selfing in populations of Corella eumyota, a recently introduced sea squirt in the English Channel. Divers Distrib 13:808-817

> Dupont L, Viard F, Dowell J, Wood C, Bishop JDD (2009) Fine- and regional-scale genetic structure of the exotic ascidian Styela clava (Tunicata) in southwest England, 50 years after its introduction. Mol Ecol 18:442-453

> Dupont L, Viard F, Davis M, Nishikawa T, Bishop JDD (2010) Pathways of spread of the introduced ascidian Styela clava (Tunicata) in Northern Europe, as revealed by microsatellite markers. Biol Invasions 12:2707-2721

- El Nagar A, Huys R, Bishop JDD (2010) Widespread occurrence of the Southern Hemisphere ascidian Corella eumyota Traustedt, 1882 on the Atlantic coast of Iberia. Aquat Invasions 5:169-173

Excoffier L, Laval G, Schneider S (2005) Arlequin ver. 3.0: an integrated software package for population genetics data analysis. Evol Bioinform Online 1:47-50

Faasse MA (2004) De Aziatische zakpijp Perophora japonica Oka, 1927 in Nederland. Het Zeepaard 64:179-181

Folmer O, Black M, Hoeh W, Lutz R, Vrijenhoek R (1994) DNA primers for amplification of mitochondrial cytochrome $c$ oxidase subunit I from diverse metazoan invertebrates. Mol Mar Biol Biotechnol 3:294-299

> Forrest BM, Gardner JPA, Taylor MD (2009) Internal borders for managing invasive marine species. J Appl Ecol 46:46-54

Fujimoto H, Watanabe H (1976) Studies on the asexual reproduction in the polystyelid ascidians, Polyzoa vesiculiphora Tokioka. J Morphol 150:607-622

Geller JB, Darling JA, Carlton JT (2010) Genetic perspectives on marine biological invasions. Annu Rev Mar Sci 2: 367-393

Gittenberger A (2007) Recent population expansions of nonnative ascidians in The Netherlands. J Exp Mar Biol Ecol 342:122-126

Glasby TM, Connell SD, Holloway MG, Hewitt CL (2007) Nonindigenous biota on artificial structures: Could habitat creation facilitate biological invasions? Mar Biol 151: 887-895

Goldstien SJ, Schiel DR, Gemmell NJ (2010) Regional connectivity and coastal expansion: differentiating pre-border and post-border vectors for the invasive tunicate Styela clava. Mol Ecol 19:874-885
Grey EK (2011) Relative effects of environment and direct species interactions on the population growth rate of an exotic ascidian. Oecologia 166:935-947

Grosholz E (2002) Ecological and evolutionary consequences of coastal invasions. Trends Ecol Evol 17:22-27

Grosholz E, Ruiz GM (1996) Predicting the impact of introduced marine species: lessons from the multiple invasions of the European green crab Carcinus maenas. Biol Conserv 78:59-66

Hall TA (1999) BioEdit: a user-friendly biological sequence alignment editor and analysis program for Windows 95/98/NT. Nucl Acids Symp Ser 41:95-98

> Holland BS (2000) Genetics of marine bioinvasions. Hydrobiologia 420:63-71

$>$ Jost L (2008) $G_{\mathrm{ST}}$ and its relatives do not measure differentiation. Mol Ecol 17:4015-4026

$>$ Keller SR, Taylor DR (2008) History, chance and adaptation during biological invasion: separating stochastic phenotypic evolution from response to selection. Ecol Lett 11: 852-866

Kolar CS, Lodge DM (2001) Progress in invasion biology: predicting invaders. Trends Ecol Evol 16:199-204

Koyama H, Watanabe H (1981) Colony specificity in the colonial ascidian, Perophora japonica. Annot Zool Jpn 54:30-41

Koyama H, Watanabe H (1982) Colony specificity in the ascidian, Perophora sagamiensis. Biol Bull (Woods Hole) 162:171-181

Koyama H, Watanabe H (1986) Studies on the fusion reaction in two species of Perophora (Ascidiacea). Mar Biol 92:267-275

> Lambert G (2005) First North American record of the ascidian Perophora japonica. J Mar Biol Assoc UK 85: 1011-1012

> Lambert G (2007) Invasive sea squirts: a growing global problem. J Exp Mar Biol Ecol 342:3-4

Lambrinos JG (2004) How interactions between ecology and evolution influence contemporary invasion dynamics. Ecology 85:2061-2070

> Lee CE (2002) Evolutionary genetics of invasive species. Trends Ecol Evol 17:386-391

Leng L, Zhang DX (2011) Measuring population differentiation using $G_{\mathrm{ST}}$ or $D$ ? A simulation study with microsatellite DNA markers under a finite island model and nonequilibrium condition. Mol Ecol 20:2494-2509

Lockwood JL, Cassey P, Blackburn T (2005) The role of propagule pressure in explaining species invasions. Trends Ecol Evol 20:223-228

López-Legentil S, Turon X (2006) Population genetics, phylogeography and speciation of Cystodytes (Ascidiacea) in the Western Mediterranean Sea. Biol J Linn Soc Lond 88:203-214

> López-Legentil S, Turon X, Planes S (2006) Genetic structure of the star sea squirt, Botryllus schlosseri, introduced in southern European harbours. Mol Ecol 15:3957-3967

> Meirmans PG, Hedrick PW (2011) Assessing population structure: $F_{\mathrm{ST}}$ and related measures. Mol Ecol Resour 11: $5-18$

Monniot C, Monniot F (1985) Apparition de l'ascidie Perophora japonica sur les cotês et dans les ports de la Manche. C R Somm Seances Soc Biogeogr Paris 61: 111-116

> Mukai H, Koyama H, Watanabe H (1983) Studies on the reproduction of three species of Perophora (Ascidiacea). Biol Bull (Woods Hole) 164:251-266 
Narum SR (2006) Beyond Bonferroni: less conservative analyses for conservation genetics. Conserv Genet 7: 783-787

Nei M (1987) Molecular evolutionary genetics. Columbia University Press, New York, NY

Nishikawa T (1991) The ascidians of the Japan Sea. II. Publ Seto Mar Biol Lab 35:25-170

> Nishikawa T, Bishop JDD, Sommerfeldt AD (2000) Occurrence of the alien ascidian Perophora japonica at Plymouth. J Mar Biol Assoc UK 80:955-956

Novak SJ (2007) The role of evolution in the invasion process. Proc Natl Acad Sci USA 104:3671-3672

> Pérez-Portela R, Turon X (2008) Cryptic divergence and strong population structure in the colonial invertebrate Pycnoclavella communis (Ascidiacea) inferred from molecular data. Zoology 111:163-178

Pérez-Portela R, Bishop JDD, Davis A, Turon X (2009) Phylogeny of the families Pyuridae and Styelidae (Stolidobranchiata, Ascidiacea) inferred from mitochondrial and nuclear DNA sequences. Mol Phylogenet Evol 50: 560-570

> Pineda MC, López-Legentil S, Turon X (2011) The whereabouts of an ancient wanderer: global phylogeography of the solitary ascidian Styela plicata. PLoS One 6:e25495

> Provan J, Murphy S, Maggs CA (2005) Tracking the invasive history of the green alga Codium fragile ssp. tomentosoides. Mol Ecol 14:189-194

- Rinkevich B (2005) Natural chimerism in colonial urochordates. J Exp Mar Biol Ecol 322:93-109

Rinkevich B, Weissman IL (1992) Allogeneic resorption in colonial protochordates:consequences of nonself recognition. Dev Comp Immunol 16:275-286

> Rius M, Pascual M, Turon X (2008) Phylogeography of the widespread marine invader Microcosmus squamiger (Ascidiacea) reveals high genetic diversity of introduced populations and non-independent colonizations. Divers Distrib 14:818-828

$>$ Roman J, Darling J (2007) Paradox lost: genetic diversity and the success of aquatic invasions. Trends Ecol Evol 22: 454-464

Roman J, Palumbi SR (2004) A global invader at home: population structure of the green crab, Carcinus maenas, in Europe. Mol Ecol 13:2891-2898

Rousset F (1997) Genetic differentiation and estimation of gene flow from $F$-statistics under isolation by distance. Genetics 145:1219-1228

Rozas J, Sanchez-Del Barrio JC, Messeguer X, Rozas R (2003) DnaSP, DNA polymorphism analyses by the coalescent and other methods. Bioinformatics 19:2496-2497

Ruiz GM, Carlton JT, Grosholz ED, Hines AH (1997) Global invasions of marine and estuarine habitats by non-indigenous species: mechanisms, extent, and consequences. Am Zool 37:621-632

Ruiz GM, Fofonoff PF, Carlton JT, Wonham MJ, Hines AH, Cohen A (2000) Invasion of coastal marine communities in North America: patterns and processes. Annu Rev Ecol Syst 31:481-531

Sakai AK, Allendorf FW, Holt JS, Lodge DM and others (2001) The population biology of invasive species. Annu Rev Ecol Syst 32:305-332

Editorial responsibility: Philippe Borsa, Montpellier, France
Sanamyan K (1998) Ascidians from the north-western Pacific region. 5. Phlebobranchia. Ophelia 49:97-116

> Sommerfeldt AD, Bishop JDD, Wood CA (2003) Chimerism following fusion in a clonal ascidian (Urochordata). Biol J Linn Soc Lond 79:183-192

Stachowicz JJ, Whitlatch RB, Osman RW (1999) Species diversity and invasion resistance in a marine ecosystem. Science 286:1577-1579

Stachowicz JJ, Fried H, Osman RW, Whitlatch RB (2002a) biodiversity, invasion resistance, and marine ecosystem function: reconciling pattern and process. Ecology 83: 2575-2590

Stachowicz JJ, Terwin JR, Whitlach RB, Osman RW (2002b) Linking climate change and biological invasions: ocean warming facilitates nonindigenous species invasions. Proc Natl Acad Sci USA 99:15497-15500

> Stefaniak L, Lambert G, Gittenberger A, Zhang H, Lin S, Whitlatch R (2009) Genetic conspecificity of the worldwide populations of Didemnum vexillum Kott, 2002. Aquat Invasions 4:29-44

Strayer DL, Eviner VT, Jeschke JM, Pace ML (2006) Understanding the long-term effects of species invasions. Trends Ecol Evol 21:645-651

Svane I, Young CM (1989) The ecology and behaviour of ascidian larvae. Oceanogr Mar Biol Annu Rev 27:45-90

Templeton AR, Sing CF (1993) A cladistic analysis of phenotypic associations with haplotypes inferred from restriction endonuclease mapping. IV. Nested analyses with cladogram uncertainty and recombination. Genetics 134: 659-669

Templeton AR, Boerwinkle E, Sing CF (1987) A cladistic analysis of phenotypic association with haplotypes inferred from restriction endonuclease mapping. I. Basic theory and an analysis of alcohol dehydrogenase activity in Drosophila. Genetics 117:343-351

- Tsutsui ND, Suarez AV, Holway DA, Case TJ (2000) Reduced genetic variation and the success of an invasive species. Proc Natl Acad Sci USA 97:5948-5953

Turon X (2005) A new mode of colony multiplication by modified budding in the ascidian Clavelina gemmae n.sp. (Clavelinidae). Invertebr Biol 124:273-283

Wallentinus I, Nyberg CD (2007) Introduced marine organisms as habitat modifiers. Mar Pollut Bull 55:323-332

Wasson K, Zabin CJ, Bedinger L, Diaz MC, Pearse SJ (2001) Biological invasions of estuaries without international shipping: the importance of intraregional transport. Biol Conserv 102:143-153

Watanabe H, Taneda Y (1982) Self or non-self recognition in compound ascidians. Am Zool 22:775-782

Weir BS, Cockerham CC (1984) Estimating F-statistics for the analysis of population structure. Evolution 38: 1358-1370

> Wilson JR, Dormontt EE, Prentis JP, Lowe AJ, Richardson DM (2009) Something in the way you move: dispersal pathways affect invasion success. Trends Ecol Evol 24: 136-144

> Zhan A, Macisaac H, Cristescu M (2010) Invasion genetics of the Ciona intestinalis species complex: from regional endemism to global homogeneity. Mol Ecol 19: 4678-4694

Submitted: September 2, 2011; Accepted: December 9, 2011 Proofs received from author(s): April 3, 2012 